\title{
Identifying Contrasting Chinese and Japanese Cultural Values: Implications for Intercultural Youth Education
}

\author{
Yuri Okunishi', Tomoko Tanaka ${ }^{2}$, Hongru Tian ${ }^{3}$, Yutian Bai ${ }^{4}$ \\ ${ }^{1}$ Department of Engineering, Okayama University of Science, Okayama, Japan \\ ${ }^{2}$ Graduate School of Humanities and Social Sciences, Okayama University, Okayama, Japan \\ ${ }^{3}$ Faculty of Asian Languages and Cultures, Zhejiang International Studies University, Hangzhou, China \\ ${ }^{4}$ Faculty of Cultural Studies, Kyoto Sangyo University, Kyoto, Japan \\ Email: yokunishi@bme.ous.ac.jp
}

Received 24 June 2015; accepted 13 September 2015; published 18 September 2015

\section{Abstract}

This study focuses on the nature of contrasting cultural values between China and Japan. Considering the values traditionally recognized as being unique and distinctive to China as well as those identified in previous research, four short stories addressing cultural conflict between Chinese and Japanese values were devised. Eight Japanese college students studying at universities in western Japan were interviewed in the winter of 2014 and were asked to openly give their interpretation of behaviors of those bound by conventional Chinese values. The qualitative analyses of the verbal data resulted in the extraction of coded concepts, which were then arranged to enable a comparison with our previous study that was similarly conducted with 18 Chinese college students. Five sets of contrasting cultural values between China and Japan were identified: 1) Respect for an individual's mianzi (face) and original opinions versus respect for group consensus and opinions; 2) Prioritization of enthusiasm over planning in maintaining friendships versus priority on appointment and efficiency; 3) Wider human networking versus limited human relationships; 4) Openness and directness among good friends versus reservation and maintenance of respectful distance; 5) Social expected repayment from children to parents versus one-way devotion from parents to children. It is considered that raising people's awareness of the historical background and social reasoning behind distinct cultural values - and the rationale behind them-would help them understand seemingly similar but, in fact, very contrasting cultural values of a neighboring country.

\section{Keywords}

Intercultural Education, Intercultural Conflict, Chinese Culture, Mianzi (Face), Guanxi (Relationship)

\section{Introduction}

The promotion of intercultural education is a key factor in opening our eyes to differences and similarities of 
other people, in order to make our world a better place to live. Various theories have been proposed to explain the nature of differences among major cultures. These theories describe differences in communication styles (low versus high cultural context), and differences in orientations (individualist versus collectivist). These theories contribute to the interpretation and understanding of broad cultural differences such as existing between western and eastern cultures, and partly describe how persons from eastern, collectivist cultures may effectively interact with persons from western, individualist cultures. Nonetheless, intercultural problems still frequently arise between cultures that seemingly share common theoretical bases, but which are distinct from each other in the details of their thoughts, values, and behavior.

Such intercultural problems are obtained between Japan and China, which share a collectivist cultural framework and low-context communication style (Hall, 1976; Hofstede \& Hofstede, 2005) [1] [2]. Despite their general categorization as eastern, collectivist, and low-context; Japan and China are in fact sufficiently culturally distinct and incompatible that nationals of each country often experience difficulty understanding the thinking, values and behavior of nationals of the other (Nakashima, 2011; Sonoda, 2001) [3] [4]. Many of Japan and China's ongoing disputes may be partly attributed to culturally derived differences in the two countries' understanding of their politics and histories.

This study examines qualitative differences between Japanese and Chinese cultures, and identifies contrasting aspects of each, by contrasting Chinese and Japanese interpretations of four short stories derived from extant research addressing Sino-Japanese intercultural conflicts (Okunishi, 2012; Okunishi \& Tanaka, 2009; Sueta, 2012) [5]-[7]. This study analyzes these differences in order to suggest potentially significant intercultural education targeting both countries.

\section{Methodology}

\subsection{Participants and Derivation of Short Stories}

Four short stories were prepared. Stories addressed the following items: Story 1: "Loss of face/mianzi," Story 2: "Dedicated relationships/guanxi with friends," Story 3: "Frank communication with close friends," Story 4: "Dedicated relationships/guanxi with parents." Participants were eight Japanese students attending universities in western Japan, majoring in psychology or engineering. Participants completed semi-structured interviews lasting approximately 30 - 60 minutes in February and March of 2014. They had not lived in a different culture, and had limited intercultural contact. They were asked to freely interpret the behavior of the above stories' central characters, who acted according to Chinese cultural values. They received explanations of the interviews' purpose and procedure; all participants provided informed consent. The stories are as follows:

$<$ Story $1>$

Mr. Liu is a Chinese student studying in the doctoral course of science and technology in a Japanese university. One day, Mr. Liu made a presentation on his research progress at a laboratory meeting for his lab's members. The audience was composed of his peers Mr. A, Mr. B, and Mr. C; his juniors Mr. D and Mr. E who were graduate students; his juniors Mr. F, Mr. G, and Mr. H who were undergraduate students; and his professor Dr. I. Mr. Liu explained his research's progress using slides, and enthusiastically discussed his ideas. The presentation finished, and it was time to listen to the audience's opinions. Mr. A said, "Mr. Liu, your work seems to need overall improvement. First, the title is not appropriate. There is also a problem in the ways of presenting tables and figures. Finally, your argument for your conclusion is invalid." Mr. Liu was surprised, and insisted, "Well, that is not true. The title is appropriate in these ways. I advanced my research in this way, and there is no mistake. Above all, the excellence of my research ideas, in fact, lies in this point.” He desperately continued justifying himself. The junior, Mr. D, then said, "Mr. Liu, Mr. A doesn't mean that. He meant that an axis of your research was no good. An axis!” "Yeah, the axis slips off,” continued Mr. F. Mr. Liu's face became bright red, and he continued saying intensely and in a raised voice, "No, no, no! This comes from this idea! Why don't you understand? Why not? Why not?" The argument continued for an hour. The professor gave a wry smile, and the other members of the audience looked troubled and sighed. No one could understand why Mr. Liu was so terribly upset. What made Mr. Liu upset? Could Mr. Liu have listened to his audience without protesting?

$<$ Story 2>

Mr. Song is Chinese, and working in Japan. He was to go to Shanghai for a business trip with six colleagues, and wrote a message in Weixin (China's equivalent of LINE, an SNS)'s chat service: "I'm going to Shanghai next week on a business trip." His college classmate, Mr. A, responded, "Let's go for a drink in Shanghai at 
night with four or five of my friends who are working in the city.” There was to be a meeting that night, however, so Mr. Song responded, “Sorry, I have a meeting that night, and I can’t go for a drink.” “OK,” Mr. A replied. When Mr. Song arrived at Shanghai, he wrote on Weixin, "I have just arrived in China and will move to Henanshang Province tomorrow. We'll go to Shanghai Museum in the morning, and catch an airplane at three o'clock.” In response to this, Mr. A sent a massage, “Tomorrow I am also working near the airport, so maybe we can meet. Contact me when you arrive at the airport.” Mr. B, who was watching the exchange of messages between Mr. Song and Mr. A, decided to surprise Mr. Song by suddenly going to Shanghai Museum to meet him. He walked around the Museum, but was finally unable to find Mr. Song. Mr. B then joined Mr. A at the airport and they both waited for Mr. Song. Mr. Song and his colleagues arrived at the airport, but the checking-in procedures took an hour, and Mr. Song was only able to meet Mr. A and Mr. B for 30 minutes. Mr. A paid for Mr. Song's and the other six people's meals and left satisfied. Mr. Song's colleagues could not understand Mr. A and Mr. B's behavior at all: why had they come to see Mr. Song, with such a high risk of not being able to meet him, walked around Shanghai Museum, and treated all of them to their meals?

$<$ Story 3>

Mami is a Japanese student studying in China. Mami likes Xiao Li, but is often very much hurt by Xiao Li's words and actions. Recently, Mami happened to see Xiao Li on campus, and said "Nihao" to her. Xiao Li then approached Mami and touched her blouse lightly with her fingers, saying, "Mami, the color of this blouse doesn't suit you. And that necklace looks like an old woman’s.” Mami did not understand why Xiao Li said such terrible things to her, and felt ridiculed. Why did Xiao Li speak and behave as she did?

$<$ Story 4>

Mr. Wang is a Chinese student studying in Japan. He makes a modest living working part-time at a restaurant. The Chinese New Year is approaching. He decides to temporarily go home, in order to celebrate the New Year with his family. He does not have enough money, so he borrows some from his friends to buy an airline ticket and a personal computer. He gives the computer to his parents when he arrives home. On hearing this story, Mr. A, who is Japanese, cannot understand why Mr. Wang went home for the New Year and bought an expensive gift for his parents while in economic difficulty.

Each of the above stories was initially devised to present one concept related to traditional or typical Chinese cultural values; however, our previous study of Chinese college students using these stories indicated that some of these stories include more than one Chinese cultural value (Okunishi \& Tanaka, 2014) [8]. For example, story 1 addresses both mianzi/face and originality of ideas, and story 2 addresses both guanxi/relationships with friends and the Chinese manner of perceiving and treating guests. Further, in order to clarify the stories' contents, the stories' characters represent the addressed cultural values in somewhat exaggerated ways.

\subsection{Analysis}

Participants' speech in interviews was recorded, and subsequently transcribed and qualitatively analyzed. Analysis identified contrasting or similar concepts to those extracted from coding conducted in our previous comparative study of Chinese students (Okunishi \& Tanaka, 2014) [8]. Both Chinese and Japanese researchers participated in discussion to ensure analytical fairness.

\section{Results and Discussion}

Our previous study, which interviewed 18 Chinese students, provided us with detailed explanations and interpretations of Chinese cultural values (Okunishi \& Tanaka, 2014) [8]. For example, mianzi is found to have two orientations: the former pertains to positive self-evaluation obtained through the admiration of people to whom one is closely connected, and the latter to negative self-evaluation caused by others' diminution of one's pride or prestige. Further, regarding guanxi/relationships with friends, the following behavior or thoughts considered distinctive to Chinese people were extracted: considerable motivation to see friends including when opportunity is limited; considering a friend of a friend one's own friend, and frankly mentioning friends' inadequacies or faults for their own good. Additionally, "filial piety toward parents” was found to refer to showing loyalty to one's parents by giving gifts or by showing parents that one is leading a good life through acts.

By contrast, interviews of Japanese students in this study using the same four stories found little or no interpretation of Chinese cultural values as they were explained by the Chinese participants. Japanese students' patterns of interpretation are shown at the left of Table 1; those of Chinese students are shown at the right. 
Table 1. Japanese students’ patterns of interpretation in contrast to those of Chinese participants.

\begin{tabular}{|c|c|c|}
\hline Story & Japanese Patterns of Interpretation & Explanation by Chinese Participants \\
\hline Story 1 & $\begin{array}{l}\text { Communication difficulty, embarrassment } \\
\text { Loss of prestige } \\
\text { Loss of mianzi (face) } \\
\text { Strong ego/short temper } \\
\text { Inexperience in receiving critical feedback } \\
\text { No clear interpretation of Mr. song's actions }\end{array}$ & $\begin{array}{l}\text { Denial of originality of research/loss of prestige } \\
\text { Loss of mianzi (face) } \\
\text { Strong ego/short temper }\end{array}$ \\
\hline Story 2 & $\begin{array}{l}\text { Enthusiasm to meet a friend } \\
\text { No clear interpretation of buying lunch for a friend's } \\
\text { friends } \\
\text { No clear interpretation of seeking a meeting without an } \\
\text { appointment } \\
\text { No clear interpretation of travelling to the Museum } \\
\text { without an appointment } \\
\text { Buying lunch for a friend's friends out of politeness } \\
\text { Buying lunch for a friend's friends out of vanity } \\
\text { The friendship is extremely special } \\
\text { No clear interpretation of why private friends would } \\
\text { involve themselves in a business trip }\end{array}$ & $\begin{array}{l}\text { Trying to meet friends even for a short time } \\
\text { Importance of guanxi (human relationships) } \\
\text { Notion of being a host: a host is supposed to treat guests } \\
\text { as a group }\end{array}$ \\
\hline Story 3 & $\begin{array}{l}\text { Making a comment for the sake of a friend } \\
\text { Divergent fashion sense from a Chinese standard } \\
\text { Making a comment without much thought } \\
\text { The Chinese way of communication is to express one's } \\
\text { opinions directly } \\
\text { Directness specifically among close friends }\end{array}$ & Directness specifically among close friends \\
\hline Story 4 & $\begin{array}{l}\text { No clear interpretation of borrowing money and buying an } \\
\text { expensive gift for parents } \\
\text { Borrowing money and buying a computer out of vanity } \\
\text { Filial piety: devotion to parents by giving a gift } \\
\text { Custom of bringing back a souvenir }\end{array}$ & $\begin{array}{l}\text { Custom of bringing back a souvenir } \\
\text { Filial piety: Devotion to parent by giving a gift } \\
\text { Filial piety: Performance to show parents that one is } \\
\text { leading a good life }\end{array}$ \\
\hline
\end{tabular}

These results indicate that generating the "correct" interpretations of Chinese cultural values is very difficult for Japanese students, and often beyond their ability. Japanese students' interpretations were wide-ranging, while those of Chinese students were fairly uniform, despite the lower number of Japanese participants.

Regarding story 1 , the majority of Chinese students recognized that the story was intended to address the issue of loss of mianzi (face). By contrast, a minority of Japanese participants attributed the problem to loss of mianzi or pride. Japanese students tended to follow the group consensus in laboratory situations as described in Story 1, rather than to overly value the originality of the ideas. Hence, some Japanese participants were unable to understand why Story 1's protagonist became angry, believing that being obedient and accepting other lab members' opinions for the benefit of his research without protest would improve his research and promote harmony with other group members.

Regarding the remaining stories, some Japanese participants were unable to interpret the characters' behavior, and simply indicated that the character's actions seemed peculiar. Such behavior as attempting to meet one's friend without an appointment, treating a friend's friends as one's own guests, making direct comments to one's close friends, and borrowing money from a friend for the sake for filial piety were found to be beyond Japanese common sense or morality.

The analysis identified the following five sets of contrasting Chinese and Japanese cultural values: 1) Respect of an individual's face and original opinions versus respect for group consensus and opinions; 2) Prioritization of enthusiasm over planning in maintaining friendships versus priority on appointment and efficiency; 3) Wider human networking versus limited human relationships; 4) Openness and directness among good friends versus reservation and maintenance of respectful distance; 5) Socially recognized repayment from child to parents versus one-way devotion from parents to children.

\section{Implications for Intercultural Education}

This study’s results suggest that Japanese students largely lack cultural knowledge of China, limiting their abili- 
ty to understand and manage instances of conflict they may encounter in daily interaction with Chinese individuals. Dedication to one's parents is not as socially or morally valued among Japanese youth as it is among Chinese, and familial devotion tends to flow only from parents to children. Japanese youth tend to be educated to consider it quite immoral to borrow money from a friend or acquaintance for any reason. Further, it is particularly difficult for young Japanese to respect and devote themselves to their parents in the Chinese manner. Although these results' generalizability is somewhat limited by sample size and interview-based data collection, a large gap in cultural values was found between Chinese and Japanese students; careful and steady diminution of these gaps will be indispensable to the intercultural education of Japanese and Chinese people.

Japanese and Chinese people's intercultural education may therefore be promoted by facilitating young people from both cultures' understanding of the opposite culture's historical background and reasons for distinct cultural values, and by raising awareness regarding the existing lack of mutual understanding of Japanese and Chinese cultural values. This may help young Chinese and Japanese understand those cultural values and practices that seem similar between the two cultures but which in fact contrast strongly. Suitable educational materials should be developed to promote effective and enjoyable intercultural education for people of each country, promoting awareness and eventual acceptance of contrasting cultural values.

\section{Acknowledgements}

This work was supported by JSPS KAKENHI (Grant-in-Aid for Challenging Exploratory Research) Grant Number 25580115.

\section{References}

[1] Hall, E.T. (1976) Beyond Culture. Anchor Books, New York.

[2] Hofstead, G. and Hofstead, G.J. (2005) Cultures and Organizations: Software of the Mind. McGraw-Hill International, UK.

[3] Nakashima, H. (2011) Chugokujintohaikanishikoshi, dougokuhitotachika. Kawade Shobo Shinsha. (In Japanese)

[4] Okunishi, Y. (2012) Japanese Hosts’ Recognition of Cultural Distinctiveness in Interpersonal Exchanges with Chinese International Students. Journal of International Student Education, 17, 99-105.

[5] Okunishi, Y. and Tanaka, T. (2014). Interpretations by Chinese College Students of Distinctively Chinese Traits Potentially Leading to Cross-Cultural Conflict: Toward a Comparative Study with Japanese Youth. The 28th International Conference of Applied Psychology, Paris.

[6] Okunishi, Y. and Tanaka, T. (2009) Coping Styles of Japanese College Students in Intercultural Contact under a Multicultural Environment: Identifying a Typology on the Basis of the AUC-GS Learning Model. Multicultural Relations, 6, 53-68.

[7] Sonoda, S. (2001) Chugokujinnoshinritokodo. Nihonhousoushuppankyoukai. (In Japanese)

[8] Sueta, K. (2012) Face and the Negotiation of Multiple Identities. Nakanishiyashuppan. (In Japanese) 